This item was submitted to Loughborough's Research Repository by the author.

Items in Figshare are protected by copyright, with all rights reserved, unless otherwise indicated.

\title{
A diesel particulate filter regeneration model with a multi-step chemical reaction scheme
}

PLEASE CITE THE PUBLISHED VERSION

PUBLISHER

Professional Engineering Publishing / @ IMECHE

VERSION

VoR (Version of Record)

LICENCE

CC BY-NC-ND 4.0

\section{REPOSITORY RECORD}

Law, Ming-Chiat, Andrew Clarke, and Colin P. Garner. 2019. "A Diesel Particulate Filter Regeneration Model with a Multi-step Chemical Reaction Scheme". figshare. https://hdl.handle.net/2134/4837. 
This item was submitted to Loughborough's Institutional Repository (https://dspace.lboro.ac.uk/) by the author and is made available under the following Creative Commons Licence conditions.

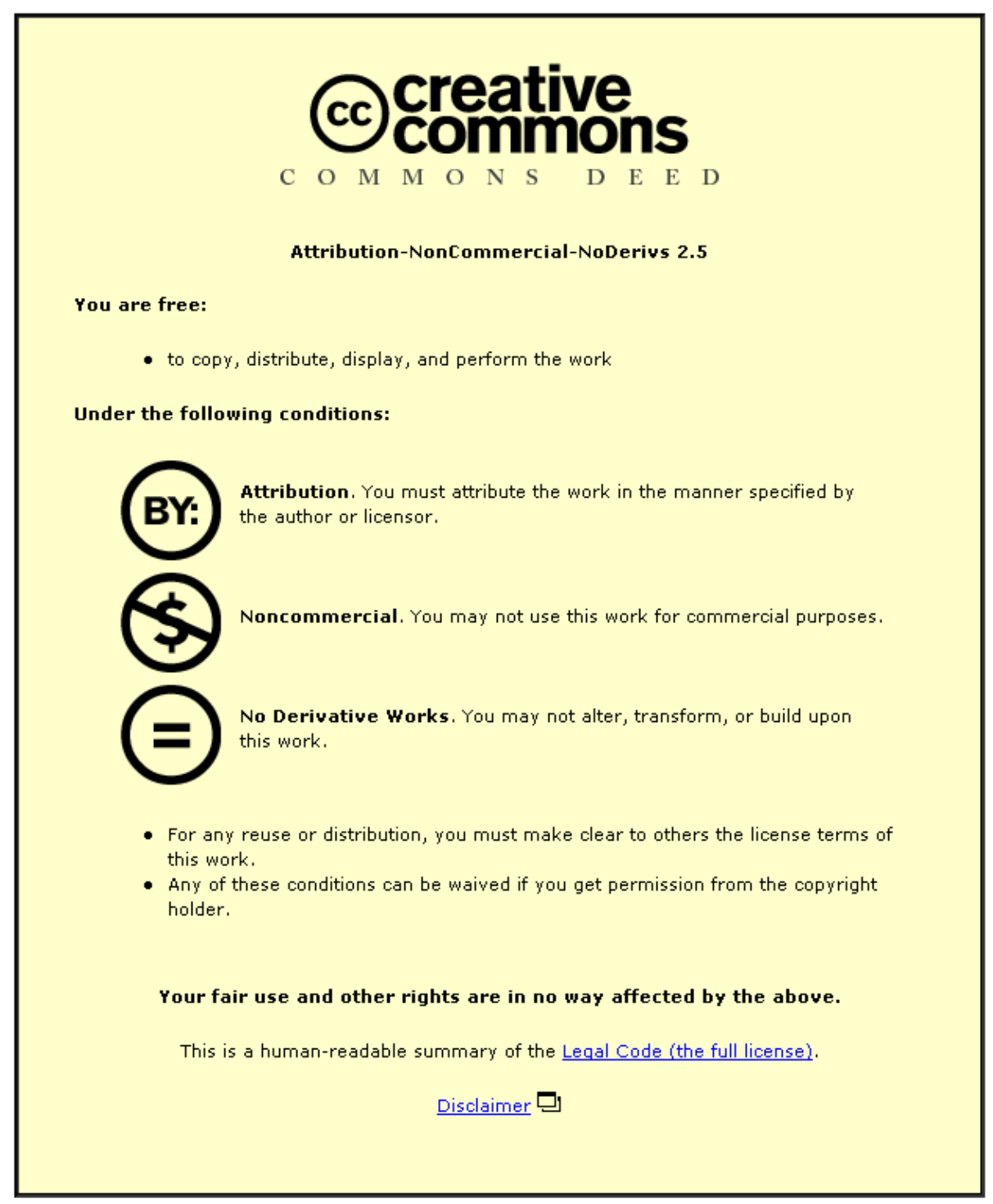

For the full text of this licence, please go to: http://creativecommons.org/licenses/by-nc-nd/2.5/ 


\title{
A diesel particulate filter regeneration model with a multi-step chemical reaction scheme
}

\author{
M C Law, A Clarke, and C P Garner* \\ Wolfson School of Mechanical and Manufacturing Engineering, Loughborough University, Loughborough, UK
}

The manuscript was received on 23 April 2004 and was accepted after revision for publication on 17 August 2004.

DOI: $10.1243 / 095440705 X 5902$

\begin{abstract}
Diesel particulate filters (DPFs) are considered necessary in order to meet future global diesel engine emissions legislation. Various regeneration methods have been developed to clean DPFs by periodic oxidation of trapped particulate matter (soot). To achieve this goal, it is important to understand the fundamentals of the regeneration process. Previous soot oxidation regeneration models relied on tunable chemical kinetic parameters to achieve agreement between model and experimental results. In the work reported in this paper, a multistep chemical reaction scheme is incorporated in a model to study the thermal regeneration process. The regeneration model does not require tunable parameters and its results compare well with experimental findings. The effects on regeneration of various gas species are also studied, in addition to $\mathrm{O}_{2}$ and $\mathrm{N}_{2}$, such as $\mathrm{CO}$ and $\mathrm{H}_{2} \mathrm{O}$ that are present in the exhaust gas. The model is also used to demonstrate the effects of quenching the regeneration process and its impact on partial filter regeneration.
\end{abstract}

Keywords: diesel, engine, particulate, filter, trap, regeneration, soot, kinetics, chemical, reaction, oxidation

\section{INTRODUCTION}

Diesel engine exhaust emission standards are becoming increasingly strict. Figure 1, for example, shows the heavy-duty diesel emission legislation for particulate matter $(\mathrm{PM})$ and oxides of nitrogen $\left(\mathrm{NO}_{\mathrm{x}}\right)$ in Japan, Europe, and the United States. This legislation is driven in part due to concerns of the effects of diesel PM on human health.

Recent years have seen significant advances in diesel emission control technology to meet the everstringent legislation. One of the ways to reduce significantly PM emissions from diesel engines is the use of a diesel particulate filter (DPF) in the exhaust system. There are a variety of DPFs available, such as the wall-flow monolith, wire mesh, and foams. Of these, the wall-flow monolith DPF exhibits the highest filtration efficiency ( $>95$ per cent by mass) for the least pressure drop. The wall-flow monolith comprises a honeycomb of square channels, typically $1-2 \mathrm{~mm}$ in square cross-section, with each end of each channel plugged alternately (see Fig. 2). In

\footnotetext{
* Corresponding author: Wolfson School of Mechanical and Manufacturing Engineering, Loughborough University, Loughborough, Leicestershire, LE11 3TU, UK. email: C.P.Garner@Lboro.ac.uk
}

this configuration, the exhaust gas flow is forced to pass through the porous ceramic walls between the channels. The pore sizes of the wall are such that they are able to filter some of the particulate in the wall. As time proceeds, the soot particulates start to accumulate on the wall surfaces. Layers of soot are formed on the wall surfaces that encourage the trapping of subsequent particulate. This gives rise to the high filtration efficiency.

If soot is allowed to accumulate too much, then both engine power and fuel economy deteriorates due to excessive exhaust gas backpressures. Hence, the filter has to be cleaned or 'regenerated'. The regeneration process, in which the trapped particulate matter oxidizes, is still poorly understood and its control a particularly difficult technical challenge. During regeneration, heat is liberated by the soot due to the exothermic oxidation process, which can lead to high thermal gradients and high temperatures and these can result in filter failure by fracture or melting. Conversely, the regeneration process can sometimes extinguish prematurely leading to incomplete filter regeneration.

The purpose of the work reported in this paper is to model the regeneration process in greater detail than previously, especially with the adoption of a more detailed multichemical reaction scheme. 

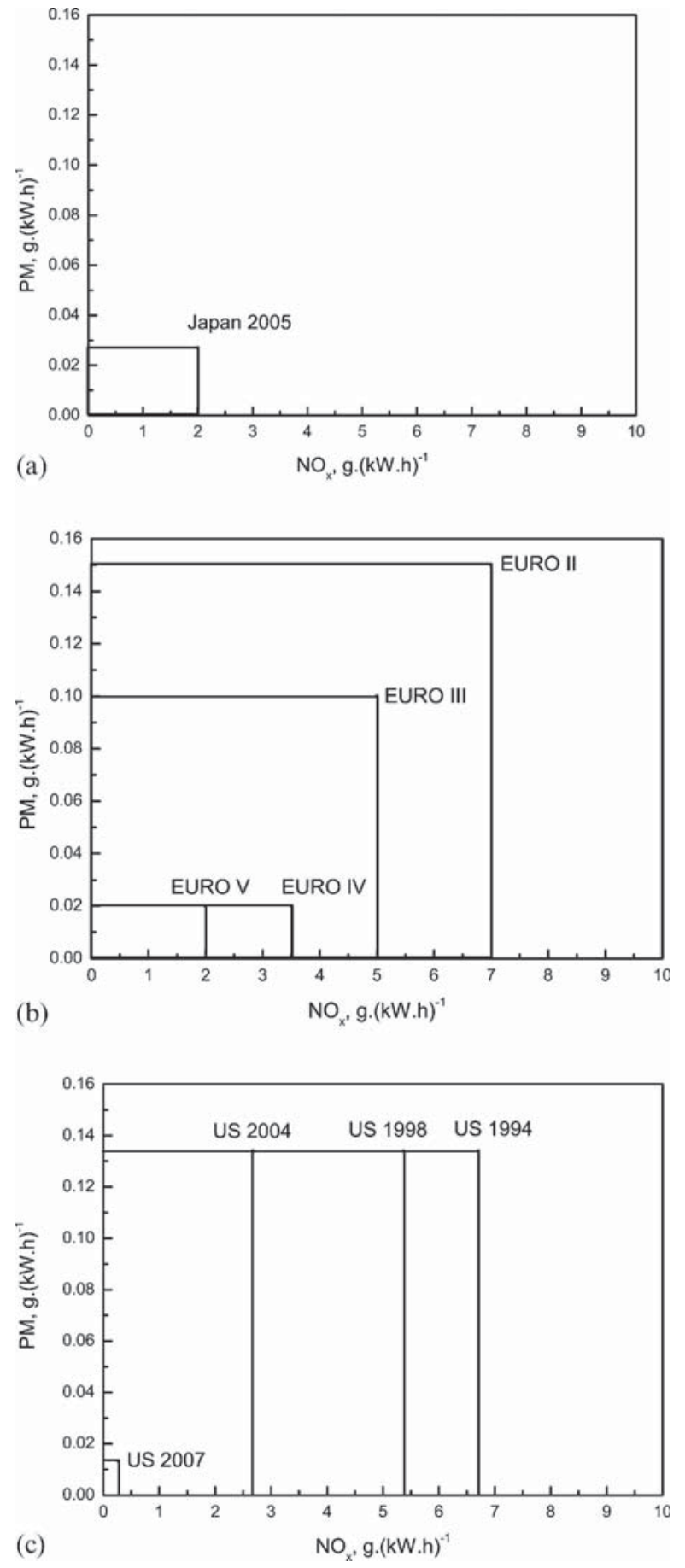

Fig. 1 Heavy duty diesel emission levels in Japan, Europe, and the US [32]

\section{DPF REGENERATION MODEL}

\subsection{Overview of the existing DPF models}

DPF modelling has been actively researched for more than two decades. Previous models span zero-, one-, two-, and three-dimensions and have been applied

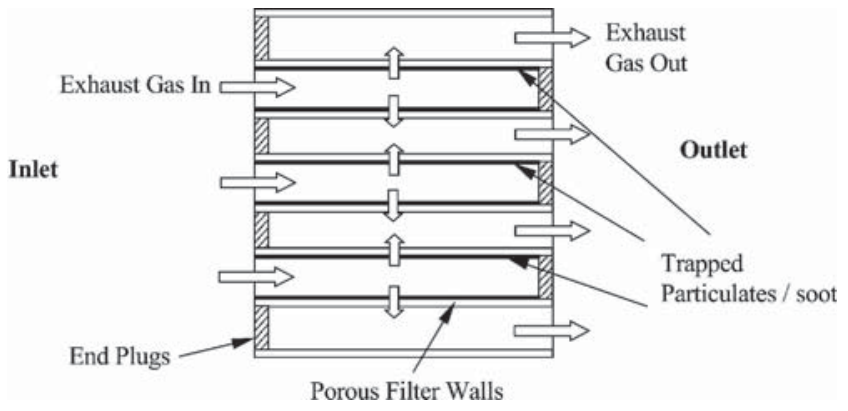

Fig. 2 Schematic of a monolithic wall-flow diesel particulate filter (DPF)

to various problems, such as thermal and catalytic regeneration and the prediction of exhaust gas flow and pressure drop across DPF, as well as optimizing the filter structural design.

Bissett and Shadman [1] and [2] reported the first mathematically rigorous one-dimensional models, which remain the foundation of current DPF modelling. Based on this model geometry, Garner and Dent [3] developed a generalized DPF model, which was applicable to not only wall-flow but also fibrous mesh DPF. Computational power has increased over the past ten years and this has allowed researchers to extend some models to multidimensions. For example, Opris and Johnson [4] developed a twodimensional regeneration model and found that regeneration can proceed from upstream to the downstream end of the filter channels. They found that after completely oxidizing the soot at the downstream end, the regeneration wave returned to upstream. This process could lead to partial regeneration of the inlet end of the DPF. By using a three-dimensional CFD model, Konstandopolous et al. [5] were able to study the temperature distribution for the whole DPF. Generally, two- and threedimensional models could give a more complete picture of the regeneration process that occurs in the DPF. However, due to the uneven exhaust gas flow distribution in the DPF, discrepancies are always observed between these models and the experimental findings, as discussed by Stratakis and Stamatelos [6]. Moreover, two- and three-dimensional models are usually quite intensive in computational effort and time. Thus, in order to obtain reasonable accuracy and predictability without being computationally intensive, one-dimensional regeneration models are of significant value.

Previous reported models lack detailed submodels of the multiple chemical reactions that take place during the regeneration process. For the thermal (i.e. non-catalytic) regeneration case, all previous models 
reported [3], [4], [7], and [8] have assumed one of or a combination of the following basic reactions

$$
\begin{aligned}
& \mathrm{C}+\mathrm{O}_{2} \rightarrow \mathrm{CO}_{2} \\
& \mathrm{C}+\frac{1}{2} \mathrm{O}_{2} \rightarrow \mathrm{CO} \\
& \mathrm{C}+\mathrm{CO}_{2} \rightarrow 2 \mathrm{CO} \\
& \mathrm{C}+\mathrm{O}_{2} \rightarrow \alpha \mathrm{CO}_{2}+(1-\alpha) \mathrm{CO}
\end{aligned}
$$

It is noted that extended chemical reaction schemes for catalytic regenerations have been developed by other researchers [9-11].

One of the limitations of the previous models is the lack of gas-phase reactions. For example, the effect of $\mathrm{CO}$ on the $\mathrm{PM} /$ soot reaction rate has been ignored. In addition, most researchers have 'tuned' (i.e. arbitrarily varied) kinetic parameters in the global reaction expressions to ensure that the model results agree with experimental findings.

The understanding of reaction kinetics during the regeneration process has become increasingly crucial, particularly due to the onset of new regeneration methods, such as catalyst-assisted [12] and non-thermal plasmas [13] and [14], etc. Thus, the objective of the work presented in this paper is to represent an extended series of chemical reaction schemes that can occur during the regeneration process.

In the following sections, a review of the overall regeneration model will be presented. This is followed by a more detailed description of the heterogeneous and homogeneous chemical reactions that have been incorporated in the model, which are

$$
\begin{aligned}
& \mathrm{C}+\frac{1}{2} \mathrm{O}_{2} \rightarrow \mathrm{CO} \quad(\mathrm{R} 1) \\
& \mathrm{CO}+\frac{1}{2} \mathrm{O}_{2} \Leftrightarrow \mathrm{CO}_{2} \quad \text { (R2) } \\
& \mathrm{C}+\mathrm{O}_{2} \rightarrow \mathrm{CO}_{2} \quad(\mathrm{R} 3) \\
& \mathrm{CO}+\mathrm{H}_{2} \mathrm{O} \Leftrightarrow \mathrm{CO}_{2}+\mathrm{H}_{2} \quad(\mathrm{R} 4) \\
& 2 \mathrm{NO}_{2}+\mathrm{C} \rightarrow 2 \mathrm{NO}+\mathrm{CO}_{2} \quad \text { (R5) } \\
& \mathrm{NO}_{2}+\mathrm{C} \rightarrow \mathrm{NO}+\mathrm{CO} \quad(\mathrm{R} 6) \\
& \mathrm{NO}_{2}+\mathrm{CO} \rightarrow \mathrm{NO}+\mathrm{CO}_{2} \quad(\mathrm{R} 7) \\
& 2 \mathrm{NO}_{+} \mathrm{O}_{2} \rightarrow 2 \mathrm{NO}_{2} \quad(\mathrm{R} 8) \\
& \mathrm{C}+\frac{1}{2} \mathrm{O}_{2}+\mathrm{NO}_{2}\left(+\mathrm{NO}_{2}\right) \rightarrow \mathrm{NO}+\mathrm{CO}_{2}\left(+\mathrm{NO}_{2}\right) \\
& \mathrm{C}+\frac{1}{2} \mathrm{O}_{2}\left(+\mathrm{NO}_{2}\right) \rightarrow \mathrm{CO}\left(+\mathrm{NO}_{2}\right) \quad(\mathrm{R} 10)
\end{aligned}
$$

Both one-step and multistep oxidation reaction submodels are studied and compared with experimental data. The effects of various gas compositions on the regeneration process are then examined. Finally, a study of the effect of quenching the regeneration process on the exhaust-gas composition is presented.

\subsection{Governing equations}

The model [3] has been generalized so that it is applicable to any type of DPF by only changing the appropriate physical properties and dimensions of the interested filter. A full description of the overall model is given by Garner and Dent [3]. Here the salient details are given for completeness of the new multichemical reaction scheme. Figure 3 shows the schematic of the model geometry used in the work reported in this paper.

\subsubsection{Regeneration mechanism}

Soot oxidation. Exhaust gas is composed of various species that could take part in the soot regeneration process. The rate of soot oxidation by reactive gas species is determined by two main factors, namely the rate of gas species transport from bulk phase to soot surface and the chemical reaction rate between the soot surface and reactive gas species in the boundary layer. The former mechanism is termed as diffusion-controlled and the latter kineticallycontrolled [15]. Thus, the rate of oxidant consumption at solid phase, $\dot{R}_{\mathrm{S}, \mathrm{j}}^{\prime \prime \prime}$ of species j during quasi-steady-state conditions (i.e. when the rate of consumption oxidants (e.g. $\mathrm{O}_{2}$ and $\mathrm{NO}_{2}$ ) equals the transport rate from bulk gas phase to solid surface) can be expressed as

$$
\dot{R}_{\mathrm{S}, \mathrm{j}}^{\prime \prime \prime}=\left(\frac{K_{\mathrm{i}} b}{K_{\mathrm{i}}+b}\right) \rho_{\mathrm{G}} m_{\mathrm{G}, \mathrm{j}}
$$

where $K_{\mathrm{i}}=A_{\mathrm{i}} \exp \left(-E_{\mathrm{a}} / R_{\mathrm{u}} T\right)$ is the Arrhenius type chemical kinetic expression of reaction i. $E_{\mathrm{a}}, A, R_{\mathrm{u}}$, and $T$ represent the activation energy, frequency factor, universal gas constant, and temperature of solid or gas, depending on whether the reaction is gas- or solid-phase reaction. If it is gas-phase reaction, $T=T_{\mathrm{g}}$ and $T=T_{\mathrm{s}}$ for solid-phase reaction. $b$ is the mass-transfer coefficient of the reaction, $\rho_{\mathrm{G}}$ is the exhaust bulk-gas density, and $m_{\mathrm{G}, \mathrm{j}}$ is the mass fraction of gas species $\mathbf{j}$.

Gas-phase reaction. The soot oxidation process produces various gas species. Some of these species are not inert and therefore they react in the gas phase (or with the solid soot) and heat is liberated (or absorbed) during the reaction. In the case of gasphase reactions, gas specie diffusion effects are considered negligible (i.e. a well-stirred reactor) and the 


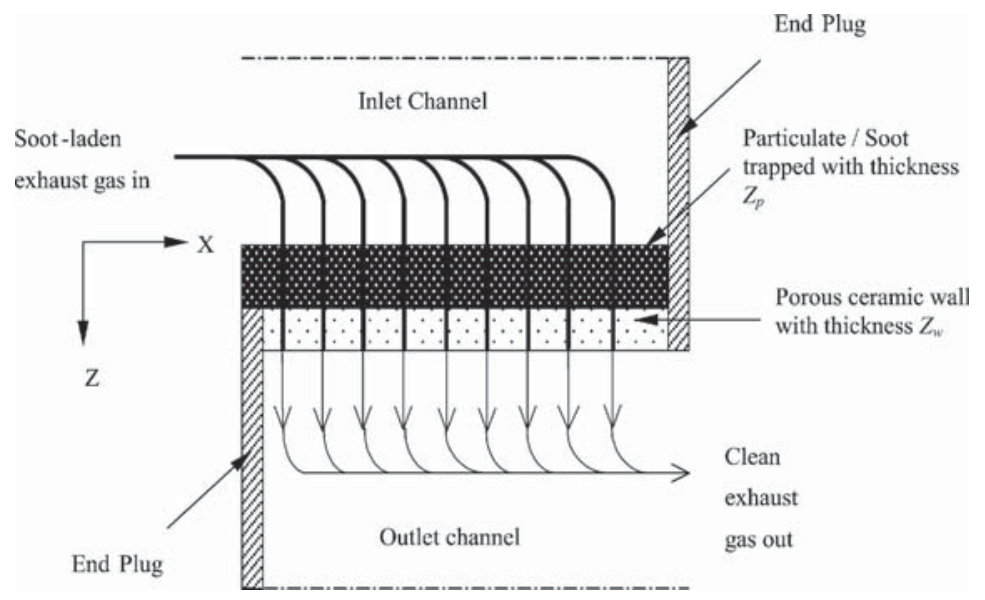

Fig. 3 Schematic for a single channel wall on which the model is based

reaction rate is solely kinetically controlled. In order to keep the model as general as possible, reversible gas-phase reactions are considered, thus

$$
\sum_{\mathrm{j}=1}^{N} \nu_{\mathrm{ji}}^{\prime} Y_{\mathrm{j}} \Leftrightarrow \sum_{\mathrm{j}=1}^{N} \nu_{\mathrm{ji}}^{\prime \prime} Y_{\mathrm{j}}
$$

where $v^{\prime}$ and $v^{\prime \prime}$ are the stoichiometric coefficients of reactant and product. $Y_{\mathrm{j}}$ is the chemical formula of species $\mathbf{j}$.

The rate of gas reaction $\mathrm{i}, \dot{R}_{\mathrm{G}, \mathrm{i}}^{\prime \prime \prime}$ is represented as

$$
\dot{R}_{\mathrm{G}, \mathrm{i}}^{\prime \prime \prime}=k_{\mathrm{fi}} \prod_{\mathrm{j}=1}^{N}\left[Y_{\mathrm{j}}\right]^{\gamma_{\mathrm{ji}}^{\prime}}-k_{\mathrm{ri}} \prod_{\mathrm{j}=1}^{N}\left[Y_{\mathrm{j}}\right]^{\nu_{\mathrm{ji}}^{\prime \prime}}
$$

where $k_{\mathrm{fi}}$ and $k_{\mathrm{ri}}$ are forward and reverse reaction rates of reaction i. $k_{\text {ri }}$ can be evaluated from the relation with equilibrium constant based on molar concentration, $K_{\mathrm{c}, \mathrm{i}},[\mathbf{1 5}]$ which is

$$
k_{\mathrm{ri}}=\frac{k_{\mathrm{fi}}}{K_{\mathrm{ci}}}
$$

This can be related to equilibrium constants based on partial pressures, $K_{\mathrm{p}, \mathrm{i}}$, by

$$
K_{\mathrm{c}, \mathrm{i}}=K_{\mathrm{p}, \mathrm{i}}\left(\frac{P}{R_{\mathrm{u}} T}\right)^{\sum \nu_{\mathrm{ij}}^{\prime \prime}-\sum v_{\mathrm{ij}}^{\prime}}
$$

where $P$ is the exhaust-gas pressure.

The equilibrium constants based on partial pressures for any arbitrary equilibrium reaction i can be calculated from

$$
\begin{aligned}
\log _{10} K_{\mathrm{p}, \mathrm{i}}= & \sum_{\mathrm{j}} v_{\mathrm{ij}}^{\prime \prime} \log _{10} K_{\mathrm{p}, \text { formation }, \mathrm{j}} \\
& -\sum_{\mathrm{j}} v_{\mathrm{ij}}^{\prime} \log _{10} K_{\mathrm{p}, \text { formation } \mathrm{j}}
\end{aligned}
$$

where $K_{\mathrm{p}, \text { formation, } \mathrm{j}}$ is the equilibrium constant based on partial pressure of species formation. By using standard thermodynamic expressions [16], $\log _{10} K_{\text {formation, }}$ can be expressed as follows

$$
\log _{10} K_{\text {formation, } \mathrm{j}}=C_{1} \ln T+\frac{C_{2}}{T}+C_{3}+C_{4} T+C_{5} T^{2}
$$

where $C_{1}, C_{2}, C_{3}, C_{4}$, and $C_{5}$ are the polynomial constants.

\subsubsection{Mass balance}

Soot. The mass of soot is depleted as it is oxidized and the oxidation rate is proportional to the sum of the solid-gas reaction rates. Thus, it can be represented by

$$
\frac{\partial \beta_{\mathrm{p}}}{\partial t}=-\sum_{\mathrm{i}} \frac{\dot{R}_{\mathrm{s}, \mathrm{j}}^{\prime \prime}}{r_{\mathrm{i}}}
$$

where $\beta_{\mathbf{p}}$ is the bulk density of soot (particulate) and $r$ is the stoichiometric ratio of the reaction i.

Exhaust gas stream. The mass balance of exhaust gas species during the regeneration process can be written as

$$
-\varphi \dot{G}_{\mathrm{G}}^{\prime \prime}\left(\frac{\partial m_{\mathrm{G}, \mathrm{j}}}{\partial z}\right)-\varphi \rho_{\mathrm{G}}\left(\frac{\partial m_{\mathrm{G}, \mathrm{j}}}{\partial t}\right)=\sum \dot{R}_{\mathrm{G}, \mathrm{j}}^{\prime \prime \prime}+\sum \dot{R}_{\mathrm{S}, \mathrm{j}}^{\prime \prime \prime}
$$

where $\varphi$ is the medium porosity, $\dot{G}_{\mathrm{G}}^{\prime \prime}$ is the gas flowrate per unit area, $m_{\mathrm{G}, \mathrm{j}}$ is the concentration of gas constituent $j$ in the bulk gas. It dictates that the net rate of production (or destruction) of a gas species $j$ is the sum of both gas and solid-gas phase reactions.

\subsubsection{Energy balance}

Gas stream. The overall filter is assumed to be well insulated and heat transfer in the gas phase is very 
small and hence neglected. The energy balance in the gas stream in both time and space equals to the heat convected to the solid phase and also the heat released (or absorbed) during reactions. This can be expressed as follows

$$
\begin{gathered}
-\varphi \dot{G}_{\mathrm{G}}^{\prime \prime} c_{\mathrm{P}_{\mathrm{G}}}\left(\frac{\partial T_{\mathrm{G}}}{\partial z}\right)-\varphi \rho_{\mathrm{G}} c_{\mathrm{P}_{\mathrm{G}}}\left(\frac{\partial T_{\mathrm{G}}}{\partial t}\right) \\
=h \cdot a\left(T_{\mathrm{G}}-T_{\mathrm{S}}\right)+\sum_{\mathrm{i}} \dot{R}_{\mathrm{i}}^{\prime \prime \prime} H_{\mathrm{i}}
\end{gathered}
$$

where $h$ is the convective heat transfer coefficient and $c_{\mathrm{P}_{\mathrm{G}}}$ is the specific heat capacity of exhaust gas. $\dot{R}_{\mathrm{i}}^{\prime \prime \prime}$ is the reaction rate, which includes $\dot{R}_{\mathrm{G}, \mathrm{j}}^{\prime \prime \prime}$ and $\dot{R}_{\mathrm{S}, \mathrm{j}}^{\prime \prime \prime}$.

Soot. Radiative heat transfer effects from the solid surfaces can be neglected since the channels are slender and each of the four surfaces of the inlet channel are assumed to exchange equal amounts of radiative heat with each other. The convective heat transfer to the solid from the gas stream increases the internal energy of the solid and hence its temperature, setting up a thermal gradient in the flow direction. If the temperature of the solid is high enough, the particulate will oxidize rapidly liberating significant energy. This is represented as

$$
\begin{aligned}
(1-\varphi) \rho_{\mathrm{S}} c_{\mathrm{P}_{\mathrm{S}}}\left(\frac{\partial T_{\mathrm{S}}}{\partial t}\right)= & \sum_{\mathrm{i}} \dot{R}_{\mathrm{i}}^{\prime \prime \prime} H_{\mathrm{i}}+h a\left[T_{\mathrm{G}}-T_{\mathrm{S}}\right] \\
& +k_{\mathrm{S}}\left(\frac{\partial^{2} T_{\mathrm{S}}}{\partial z^{2}}\right)
\end{aligned}
$$

where $k_{\mathrm{S}}$ is the thermal conductivity and $a$ is the specific area of either the soot layer or the ceramic filter wall depending on the position of $z$.

\subsubsection{Equation of state}

Exhaust gas pressure is considered constant in this model since experiments [17] have shown that the pressure change is only a few centimeters mercury. The equation of state of the system is thus defined as

$$
\rho_{\mathrm{G}} T_{\mathrm{G}}=\mathrm{constant}
$$

\subsubsection{Chemical reaction kinetic parameters}

The reaction kinetic parameters, i.e. activation energy, $E$, and frequency factor, $A$, of diesel soot oxidation with various gas species in the literature are not available in the literature. Since the majority of diesel soot consists of carbon, it is assumed, therefore, that diesel soot is similar to coal or synthetic carbon black. Although this does not precisely represent the actual diesel soot reactions in DPF, the model, however, uses the kinetic parameters that have been obtained from fundamental data. In other words, the 'tuning' of global reaction that has been widely practiced in previous models has been eliminated in this present new model.

To facilitate the kinetic modelling, detailed processes such as surface reaction and elementary gasphase reactions have been ignored. Instead, multistep global reactions for both solid-gas- and gasphase reactions are implemented. The full set of reactions considered in this model, together with the kinetic data, is given in Table 1

Reactions $\mathrm{R} 1$ and $\mathrm{R} 3$ respectively represent the partial and complete soot oxidation that produces $\mathrm{CO}$ and $\mathrm{CO}_{2}$. The kinetic empirical data of $\mathrm{R} 1$ for diesel soot has not been reported to date. Therefore, it is difficult to know which of these two reactions are more favoured during the DPF regeneration process. However, in the case of carbon graphite particle combustion in the fluidized bed, it was found that $\mathrm{CO}$ is the main product between $1000 \mathrm{~K}$ and $1400 \mathrm{~K}$ [18]. Hence it is assumed that R1 is the main PM oxidation path.

Another important issue is the disagreement in reaction order of PM with respect to oxygen. A 2/3reaction order indicates that the oxidation occurs on the particle surface and particle shrinks in size as oxidation proceeds. One the other hand, a unity reaction order means that the reaction rate is proportional to the mass of the particle [19]. The reaction order of $\mathrm{R} 1$ and $\mathrm{R} 3$ with respect to $\mathrm{O}_{2}$ is assumed to be unity.

R2 represents the oxidation of $\mathrm{CO}$ to $\mathrm{CO}_{2}$. Literature has shown that direct $\mathrm{CO}$ oxidation such as $\mathrm{CO}+\mathrm{O}_{2} \rightarrow \mathrm{CO}_{2}+\mathrm{O}$ is extremely slow [15]. The $\mathrm{CO}$ oxidation is aided by the presence of $\mathrm{OH}$ radicals via reaction $\mathrm{CO}+\mathrm{OH} \Leftrightarrow \mathrm{CO}_{2}+\mathrm{H}$. In this study, the source of $\mathrm{OH}$ radicals is assumed to be generated from R4. From Table 1, it can be observed that the $\mathrm{CO}$ oxidation is a complex reaction because of its dependence on the $\mathrm{CO}, \mathrm{H}_{2} \mathrm{O}$, and $\mathrm{O}_{2}$ concentrations raised to some empirical constants. The reversible reaction is added in the reaction by introducing a reversible reaction rate.

R4 is the water-gas shift (WGS) reaction. Since water concentration aids the CO oxidation, the WGS reaction is included in the reaction scheme to better estimate the amount of water vapour participating in the regeneration process. The kinetic data was obtained by Graven and Long [20] at a pressure of 1 atmosphere and at $900{ }^{\circ} \mathrm{C}$.

R5-R10 are $\mathrm{NO}_{\mathrm{x}}$-related reactions. Except for R7 and R8, the reactions are direction oxidation of PM 


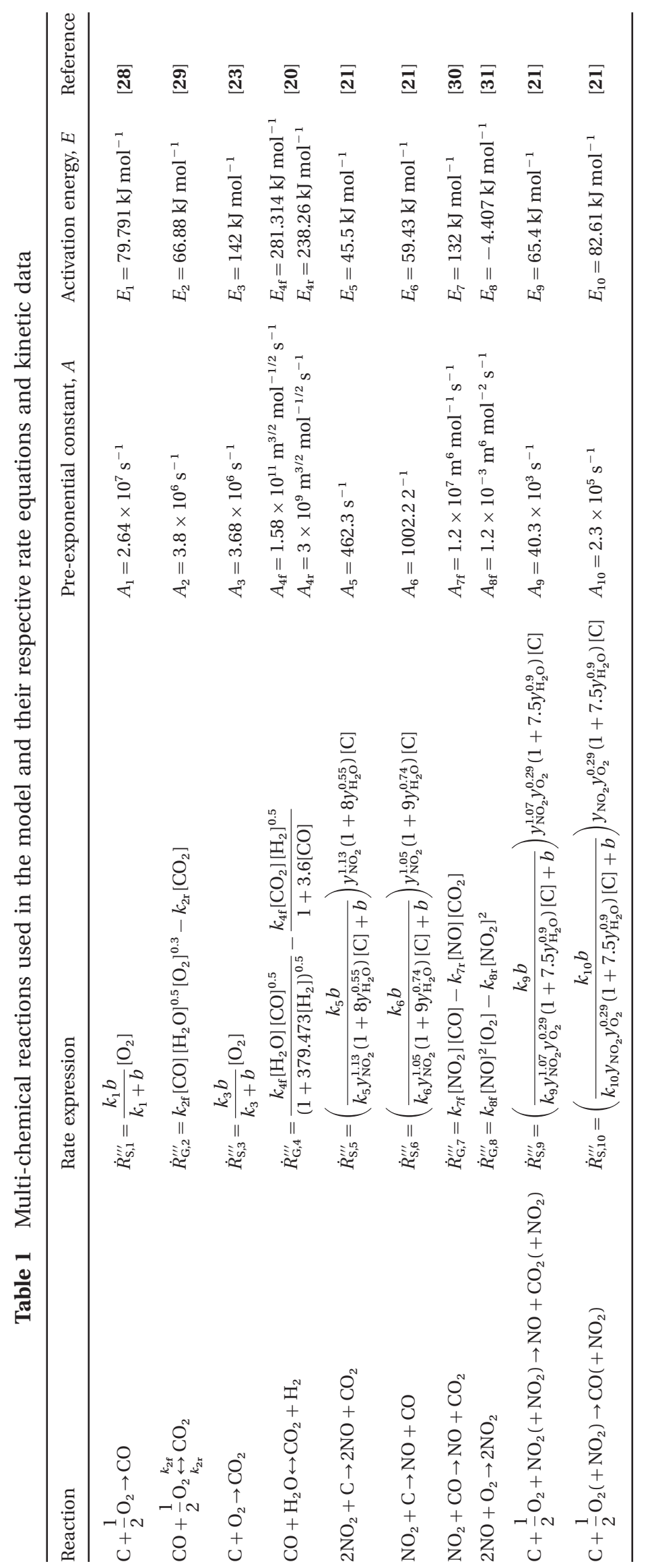


with $\mathrm{NO}_{2}$. The $\mathrm{NO}_{2}-\mathrm{C}$ kinetic data was obtained by Jacqout et al. [21] measuring the reaction rate of carbon black (Cabot Vulcan 6) in isothermal condition $\left(300-450^{\circ} \mathrm{C}\right)$. The influence of kinetic data of the reaction in the presence of water and oxygen was also measured. The kinetic data used in this study is based on their published data and with no further numerical modification.

\section{MODEL VALIDATION}

The model has been compared with two sets of carefully controlled experimental results reported by Higuchi et al. [17]. The boundary conditions of both experiments are given in Table 2.

The exhaust gas was assumed to be the combustion product of diesel fuel $\left(\mathrm{C}_{12} \mathrm{H}_{26}\right)$. The equilibrium product composition of the diesel fuel was generated using TPEQUIL [15]. The soot bulk density was experimentally found to be $56 \mathrm{~kg} \mathrm{~m}^{-3}[\mathbf{3}]$ and the soot bulk porosity is assumed to be 0.5 . The exhaust composition is given in Table 3 .

The model results were compared with the wall temperature measurement at the centre and the end of the filter (points 2 and 3 respectively), as shown in Fig. 4.

Table 2 DPF properties and exhaust-gas boundary conditions by Higuchi et al. [17]

\begin{tabular}{ll}
\hline Filter type & Ceramic wall-flow \\
\hline Overall filter dimensions $(\mathrm{mm})$ & diameter, 118; \\
& length, 152 \\
Cell density (cells.cm & -2 \\
Wall thickness $(\mathrm{mm})$ & 31 \\
Wall porosity & 0.3048 \\
Mean pore diameter $(\mu \mathrm{m})$ & $0.40-0.50$ \\
Inlet gas final temperature $(\mathrm{K})$ & $15-30$ \\
Exhaust gas flow rate at STP $\left(\mathrm{m}^{3} \cdot \mathrm{min}^{-1}\right)$ & 863 \\
Oxygen concentration $(\%)$ & 0.6 \\
Soot mass loading $(\mathrm{g})$ & 10 \\
\hline
\end{tabular}

Table 3 Base-line exhaust-gas species concentration DPF inlet boundary conditions used in the multichemical scheme simulation

\begin{tabular}{ll}
\hline Exhaust gas specie & Mole fraction $(-)$ \\
\hline Oxygen & 0.09085 \\
Water vapour & 0.07803 \\
Carbon dioxide & 0.07202 \\
Carbon monoxide & 0.0 \\
Nitrogen & 0.7591 \\
\hline
\end{tabular}

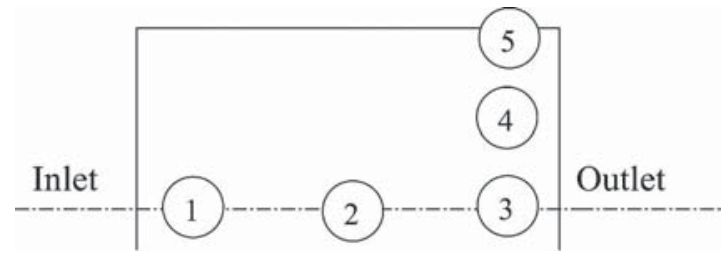

Fig. 4 Thermocouple locations in wall-flow DPF used by Higuchi et al. [17]

The exhaust gas condition at the outlet channel was compared with the experimental results. From Fig. 5, it can be observed that reasonable agreement was achieved between the multistep chemical reaction model and the experimental data obtained by Higuchi et al. [17]. At the current stage, it is unclear what factors contribute to the temperature lag between the experimental findings and the model. The temperature difference can be minimized by arbitrary tuning of some input data or the heat transfer submodel. Hence, experimental work is currently being carried out by the authors to address this and will be reported at a later date.

A number of factors can contribute to the difference between experimental and model results. First, the difference of temperature profiles between these two cases is due to the heat-transfer-mass coefficient used in the model. The coefficient used is based on that of Olson et al. [22], who studied the regeneration of adiabatic fixed beds whose carbon particles were larger than the mean diesel soot particle size. Second, diesel PM is different from other carbon materials, such as carbon black, in term of chemical species composition and microstructure. Diesel PM has chemical components that differ from artificially

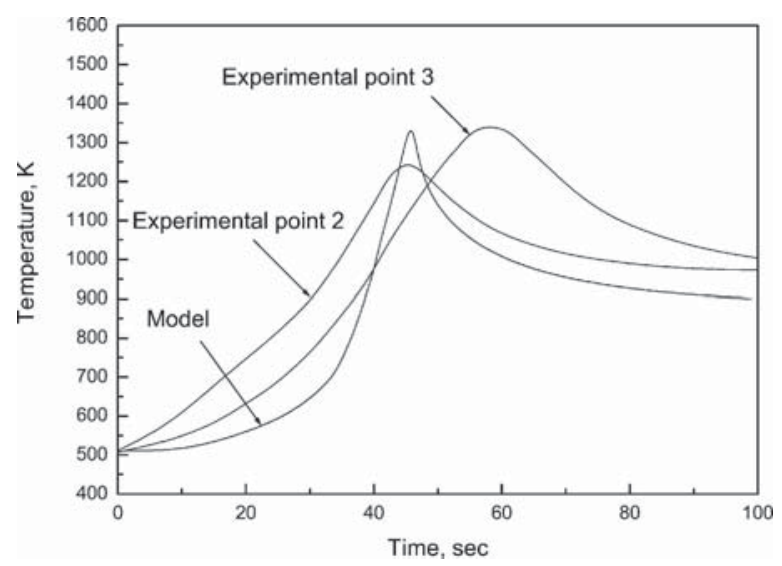

Fig. 5 Comparison of multi-step regeneration model with the experimental results by Higuchi et al. [17] 
manufactured carbon. For example, diesel PM contains organic compounds and traces of precious metals. Precious metals can have catalytic effects on the regeneration process. For example, the PM reaction rate with oxygen was found to be about $20 \mathrm{~kJ} \mathrm{~mol}^{-1}$ by Otto et al. [23] compared to that of other material such as Printex-U (a flame soot) with an activation energy of $168 \mathrm{~kJ} \mathrm{~mol}^{-1}$. Also, during the preheating of diesel PM, the absorbed volatile hydrocarbon is oxidized and heat is liberated, which in turn increases the temperature in the filter.

Ishiguro et al. [24] found that the inner core of diesel PM was less thermodynamically stable and hence could be burnt off preferentially than the outer shell. Hence, the diffusion of gas can affect the rate of regeneration process.

The above factors result in the observations made by Yezerets et al. [25]. In the experiment they conducted, two values of activation energies were obtained for soot oxidation rate. The lower value of activation energy was found at the range of $21-39 \mathrm{~kJ} \mathrm{~mol}^{-1}$ for $200-300{ }^{\circ} \mathrm{C}$, whilst $92-97 \mathrm{~kJ} \mathrm{~mol}^{-1}$ for $400-550^{\circ} \mathrm{C}$.

The previously reported one-step chemical reaction model [3] was run for comparison with the new multistep chemical reaction model. In the one-step model, the global kinetic data for R3 (Table 1) were obtained from under the engine exhaust gas conditions. As can be observed from Fig. 6, the one-step model over-predicts the peak filter temperature, as well as the time when the peak temperature occurs. Thus, the multistep chemical reaction scheme model is a more promising solution compared to the previous one-step model. As will be seen later in this paper, it also provides significantly more detailed understanding of the regeneration process and increases its generality.

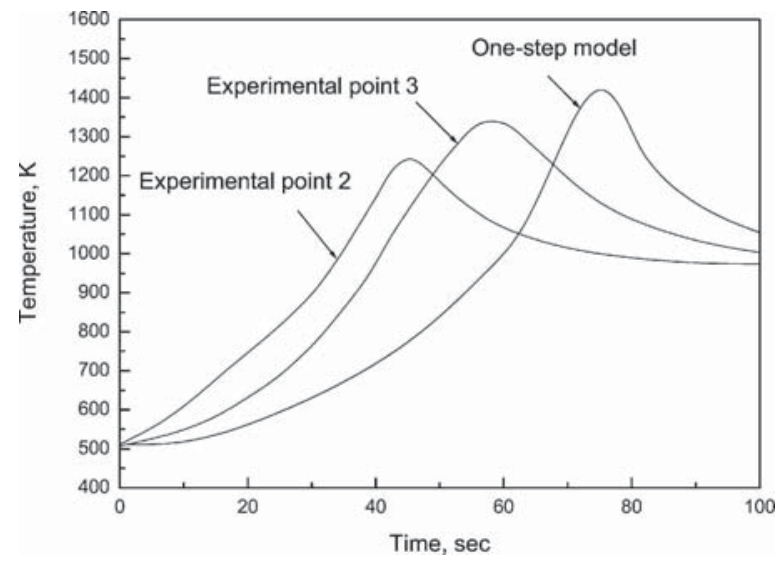

Fig. 6 Comparison of one-step regeneration model reported by Garner and Dent [3] with experimental results by Higuchi et al. [17]

\section{INCORPORATING VARIOUS EXHAUST GAS SPECIES INTO THE MODEL}

The multistep chemical scheme was used to investigate DPF regeneration behaviour under actual exhaust-gas conditions. The exhaust-gas composition and hence DPF input operating conditions were obtained experimentally and are summarized in Table 4 . The weighted engine emissions test-cycle average values were used in the simulations here. The enhanced soot oxidation rate by $\mathrm{NO}_{2}$ will be discussed in a future paper; here the effects of $\mathrm{CO}, \mathrm{CO}_{2}$, $\mathrm{H}_{2} \mathrm{O}$, and $\mathrm{H}_{2}$ on the regeneration rate are also discussed, since they are of interest to some advanced diesel engine combustion concepts currently being developed that exhibit higher engine-out levels of these species. The unvalidated results here give useful a priori guidance on the relative impact these species might have on the regeneration process.

\section{1 $\mathrm{CO}$ and $\mathrm{CO}_{2}$ effects}

Engine exhaust gas can have varying amounts of $\mathrm{CO}$ and $\mathrm{CO}_{2}$ and hence it is valuable to study the effect of $\mathrm{CO}$ and $\mathrm{CO}_{2}$ on filter regeneration. Such effects are indicated in Figs 7 and 8.

Figure 7 shows the effect of varying $\mathrm{CO}_{2}$ concentration in the exhaust gas. By increasing $\mathrm{CO}_{2}$ from 5.575 per cent (by volume) to 8.363 per cent, i.e. a 50 per cent increase, the maximum exhaust gas temperature at channel outlet decreased from $879 \mathrm{~K}$ to $862 \mathrm{~K}$. Due to the efficient fuel oxidation in modern diesel engines, the concentration of $\mathrm{CO}$ in exhaust gas is usually small, of the order of a few hundred ppm. Figure 8 shows that there is no change in channel gas temperature when the $\mathrm{CO}$ was increased from 0 to $100 \mathrm{ppm}$. A more significant increase in

Table 4 Weighted emissions test-cycle average values of diesel engine exhaust composition for heavy duty 4-cylinder, 4-stroke, 4-valve per cylinder DI engine rated at $95 \mathrm{~kW}$

Exhaust gas bulk condition

\begin{tabular}{ll}
\hline Exhaust gas inlet temperature (K) & 660.5 \\
Final steady-state exhaust temperature (K) & 773.0 \\
Inlet pressure (kPa) & 108.5 \\
Exhaust mass flow $\left(\mathrm{kg} \cdot \mathrm{h}^{-1}\right)$ & 393.7 \\
\hline Exhaust gas species composition (by volume) & \\
\hline Oxygen (\%) & 12.38 \\
Carbon dioxide (\%) & 5.575 \\
Water vapour (\%) & 4.8 \\
Nitrogen & Equilibrium \\
Carbon monoxide (ppm) & 295.3 \\
Nitrogen dioxide (ppm) & 31.6 \\
Nitrogen monoxide (ppm) & 282.65 \\
\hline
\end{tabular}




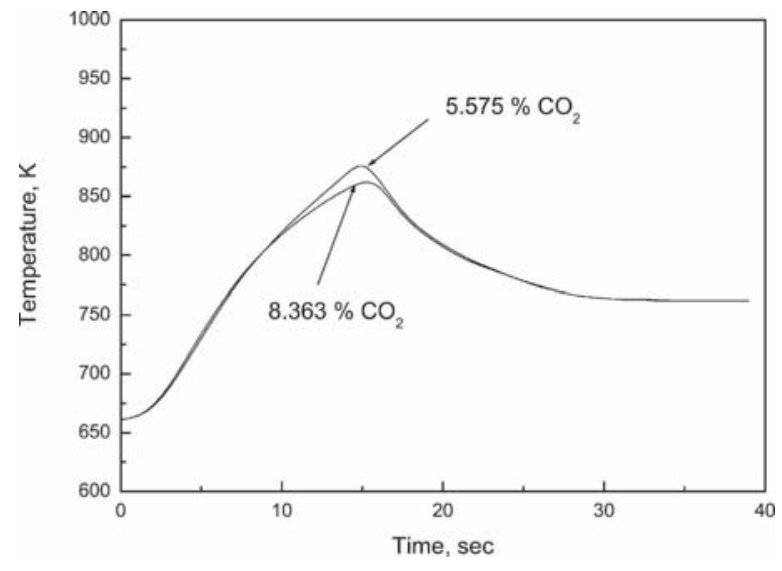

Fig. 7 The effect of carbon dioxide on the filter temperature

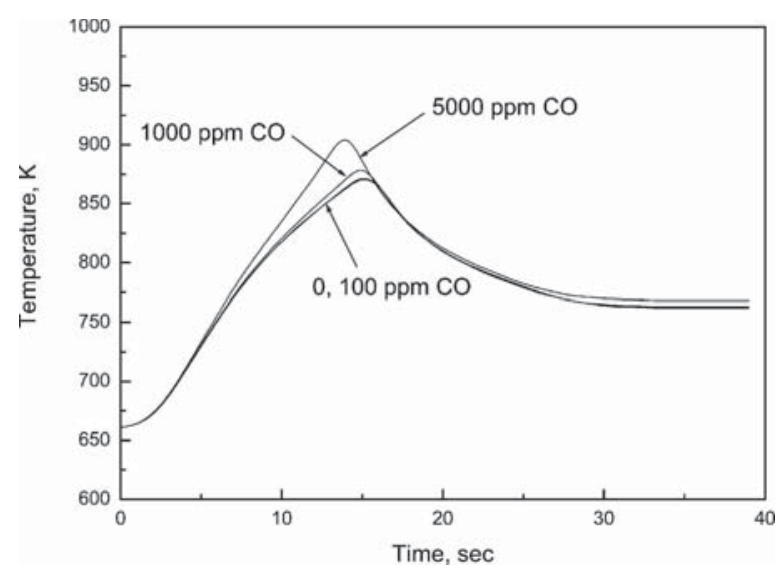

Fig. 8 The effect of carbon monoxide on the filter temperature

temperature is observed by the case of 1000 and 5000 ppm CO; such CO values might occur in some regeneration system strategies that require the engine to periodically run at rich air/fuel ratios.

Generally, it can be concluded that higher CO concentration will increase filter temperature. On the other hand, increasing $\mathrm{CO}_{2}$ will decrease the filter temperature. These trends are understandable thermodynamically since formation of $\mathrm{CO}_{2}$ is more favoured than $\mathrm{CO}$ and thereby $\mathrm{CO}$ is oxidized and heat is liberated. The specific heat capacity of $\mathrm{CO}_{2}$ is higher and thus filter temperature is reduced as $\mathrm{CO}_{2}$ is increased.

\section{$4.2 \quad \mathrm{H}_{2} \mathrm{O}$ effects}

A number of previous investigators [25-27] have reported that the presence of water vapour might enhance the regeneration rate. To investigate this, the present model was used.

Increasing the water vapour concentration in the exhaust flow entering the DPF increased the filter temperature (see Fig. 9) but had negligible effect on the overall rate of soot oxidation time (see Fig. 10). The former result can be explained as follows: water molecules are dissociated to produce hydroxyl ions, which are reactive and can promote the oxidation of $\mathrm{CO}$ to $\mathrm{CO}_{2}$. Second, as the water concentration decreases, (water-gas) equilibrium shifts to the left, which favours the production of water and $\mathrm{CO}_{2}$, which is also an endothermic reaction. Nevertheless, examining the reaction rate of the backward reaction of the water-gas shift, it can be noted that the rate is small (due to low concentration of hydrogen in the exhaust gas) thereby the contribution of this factor is small. Despite higher water vapour concentration resulting in higher heat liberation, the soot oxidation rate is not significantly faster. Hence, it can be concluded that the presence of water in exhaust gas stream aids the regeneration process and helps to convert poisonous $\mathrm{CO}$ to $\mathrm{CO}_{2}$. This is favourable, especially since $\mathrm{CO}$ is becoming a more significant emission for diesel engines due to the ever-stringent

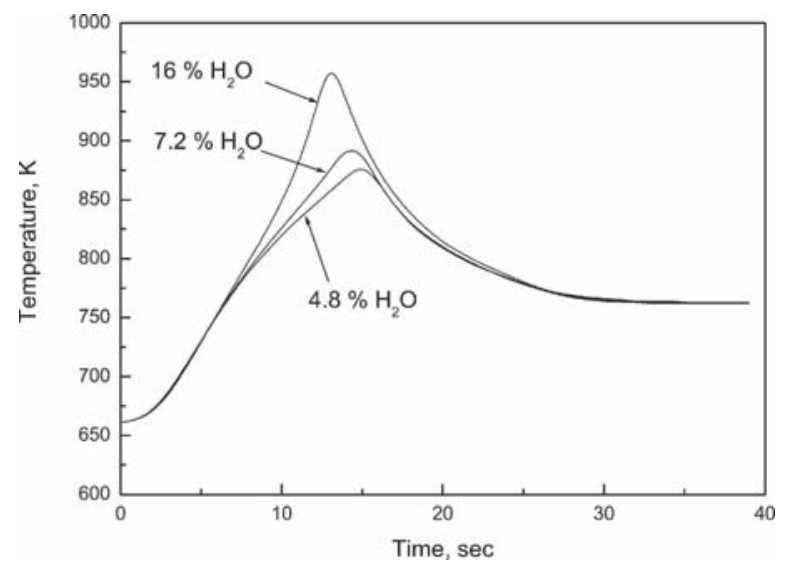

Fig. 9 Increasing water vapour concentration increases the filter temperature

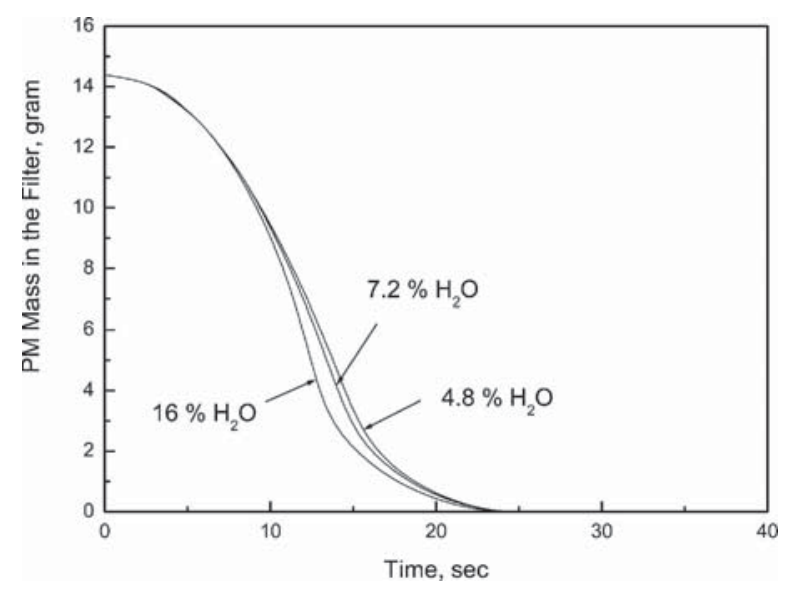

Fig. 10 Effect of inlet water vapour concentration on soot oxidation (regeneration) rate 
legislation. However, its concentration should be kept to a minimum to lower the filter temperature and avoid filter damage.

\section{3 $\quad \mathrm{H}_{2}$ effects}

Since the concentration of hydrogen in exhaust gas is usually negligible, hence it does not play an important role in the normal regeneration processes, as illustrated in Fig. 11. This result is expected since the WGS is a high temperature reaction, as indicated by its high activation energy. In addition to the temperature effects, the concentration of $\mathrm{H}_{2}$ is also important in order for the WGS to be important in the regeneration process. If, for example, the $\mathrm{H}_{2}$ concentration is sufficiently high, then by Le Chatelier's principle, WGS will shift such that production of $\mathrm{CO}$ and $\mathrm{H}_{2} \mathrm{O}$ is more favoured. This in turn will encourage the $\mathrm{CO}$ oxidation and more heat will be released and hence increases the filter temperature.

\section{TEMPERATURE EFFECTS ON EXHAUST GAS SPECIES}

In this section, the effect of the reducing exhaust-gas temperature during the rapid regeneration period is studied to simulate and investigate the quenching process that can lead to incomplete regeneration.

Figure 12 shows the DPF inlet gas-temperature boundary condition used to simulate potential quenching during rapid regeneration. The inlet gas temperature was first raised from $660 \mathrm{~K}$ to $763 \mathrm{~K}$ in $5 \mathrm{~s}$ to promote rapid regeneration (oxidation), continued for about $5 \mathrm{~s}$ and then reduced to 423 in $5 \mathrm{~s}$. The filter temperature continued to increase to $809 \mathrm{~K}$ after the exhaust flow was quenched. After that, it decreased gradually. The soot regeneration stopped

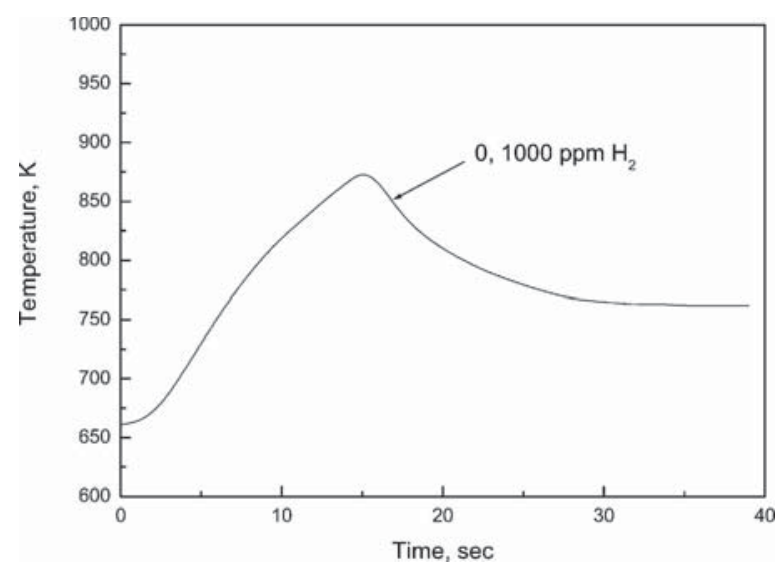

Fig. 11 The effect of inlet $\mathrm{H}_{2}$ concentration on the gas temperature in the filter

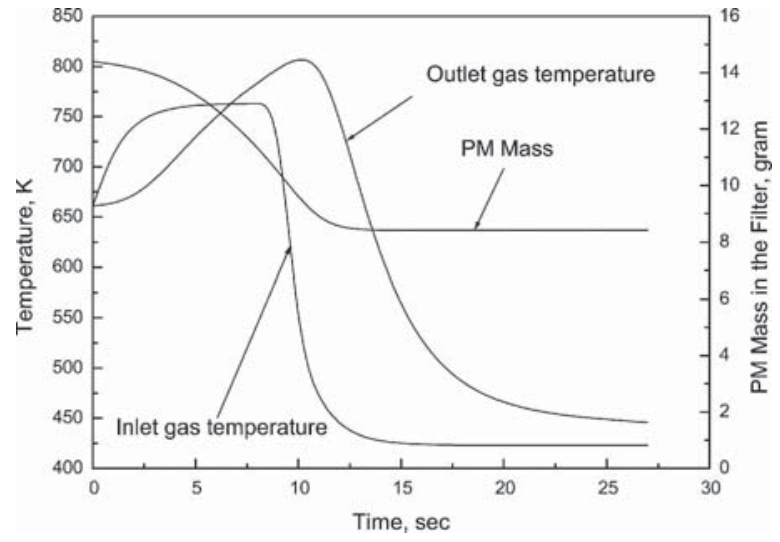

Fig. 12 Effect of premature quenching of regeneration process on filter temperature and total soot mass in filter. Inlet gas temperature increased to $763 \mathrm{~K}$ from $660 \mathrm{~K}$ in $5 \mathrm{~s}$, kept constant for about $5 \mathrm{~s}$ to promote rapid oxidation, then reduced to $423 \mathrm{~K}$ in $5 \mathrm{~s}$

when the exhaust gas flow was too cold (i.e. when it reached $423 \mathrm{~K}$ ), leaving approximately 60 per cent of the original $14 \mathrm{~g}$ of soot remaining in the filter.

For the case of carbon monoxide and carbon dioxide (see Fig. 13), it can be observed that the concentration of $\mathrm{CO}$ and $\mathrm{CO}_{2}$ decreased when the exhaust gas was quenched. In addition, it can be observed that the concentration of $\mathrm{CO}$ fell below its initial value while that of $\mathrm{CO}_{2}$ is the same as its input value. This is because $\mathrm{CO}_{2}$ is more favoured thermodynamically than CO. Validation of these predictions is currently being addressed experimentally.

\section{CONCLUSIONS}

A multistep chemical reaction scheme has been incorporated into a diesel particulate filter (DPF) regeneration model. The model is based on fundamental kinetic data and therefore it has no further

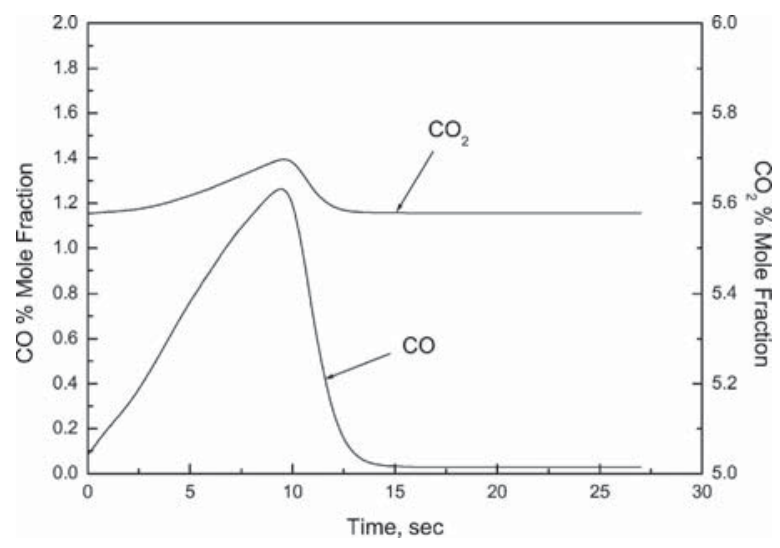

Fig. $13 \mathrm{CO}$ and $\mathrm{CO}_{2}$ profiles during quenching 
arbitrarily 'tuned' global reaction parameters. The model has been compared with other experimental findings and the agreement is reasonably good, with acknowledged limitations.

The effects of various gas species on the DPF regeneration behaviour have been studied. For the case of the thermal regeneration process, $\mathrm{CO}_{2}$ is found to have a heat sink effect, whereas $\mathrm{CO}$ is found to increase filter temperature. On the other hand, the model suggests that the water concentration should be kept to a minimum so that it does not cause high temperatures in the filter. Exhaust gas, $\mathrm{H}_{2}$, is found to have a negligible effect on regeneration.

The model is able to predict more detailed chemical processes occurring during regeneration. It has also been used to illustrate the effect of prematurely quenching the regeneration process by reducing the filter-inlet gas temperature, thereby leading to partial filter regeneration.

\section{ACKNOWLEDGEMENTS}

The authors gratefully acknowledge Perkins Engines and the Royal Academy of Engineering for their financial support of the third author.

\section{REFERENCES}

1 Bissett, E. J. Mathematical model of the thermal regeneration of a wall-flow monolith diesel particulate filter. Chem. Eng. Sci., 1984, 39(7/8), 1233-1244.

2 Bissett, E. J. and Shadman, F. Thermal regeneration of diesel particulate monolithic filters. AIChE J., 1985, 31(5), 753-758.

3 Garner, C. P. and Dent, J. C. A thermal regeneration model for monolithic and fibrous diesel particulate traps. SAE Trans., J. Passenger Cars, 1988, 97(4), 9-24.

4 Opris, C. N. and Johnson, J. H. A 2-D computational model describing the heat transfer, reaction kinetics and regeneration characteristics of a ceramic diesel particulate trap. SAE Paper, 1998, no. 980546.

5 Konstandopolous, A. G., Kostoglou, M., Housiada, P., Vlachos, N., and Zarvalis, D. Multichannel simulation of soot oxidation in diesel particulate filters. SAE Paper, 2003, no. 2003-01-0839.

6 Stratakis, G. A. and Stamatelos, A. M. Flow distribution effects in the loading and catalytic regeneration of wall flow diesel particulate filters. Proc. Instn Mech. Engrs, Part D: J. Automotive Engineering, 2004, 218, 203-216.

7 Pontikakis, G., Stamatelos, A., Bakasis, K., and Aravas, N. 3-D catalytic regeneration and stress modeling of diesel particulate filters by ABAQUS FEM software. SAE Paper, 2002, no. 2002-01-1017.
8 Jørgensen, M. W. and Sorenson, S. C. A 2-dimensional simulation model for a diesel particulate filter. SAE Paper, 1997, no. 970471.

9 Haralampous, O. A., Koltsakis, G. C., Samaras, Z. C., Vogt, C.-D., Ohara, E., Watanabe, Y., and Mizutani, T. Reaction and diffusion phenomena in catalyzed diesel particulate filters. SAE Paper 2004, no. 2004-01-0696.

10 Haralampous, O. A., Koltsakis, G. C., Samaras, Z. C., Vogt, C.-D., Ohara, E., Watanabe, Y., and Mizutani, T. Modeling and experimental study of uncontrolled regenerations in SiC filters with fuel borne catalyst. SAE Paper, 2004, no. 2004-01-0697.

11 Pontikakis, G. N. Modeling, reaction schemes and kinetic parameter estimation in automotive catalytic converters and diesel particulate filters, Doctoral Thesis, University of Thessaly, 2003.

12 Cooper, B. J. and Thoss, J. E. Role of NO in diesel particulate emission control. SAE Paper, 1989, no. 890404.

13 Hoard, J. Plasma-catalysis for diesel exhaust treatment: current state of the art. SAE Paper, 2001, no. 2001-01-0185.

14 Hammer, T. Non-thermal plasma application to the abatement of noxious emissions in automotive exhaust gases. Plasma Sources Sci. Technol., 2002, 11, A196-A201.

15 Turns, S. R. An introduction to combustion, 2nd edition, 2000 (McGraw-Hill International Editions).

16 Stull, D. R., Chao, J., Dergazarian, T. E., Plessis, L. A. D., Hadden, S. T., and Justice, B. H. JANAF Thermochemical Tables. 1965 (National Bureau of Standards, USA).

17 Higuchi, N., Mochida, S., and Kojima, M. Optimized regeneration conditions of ceramic honeycomb diesel particulate filters. SAE Paper, 1983, no. 830078

18 Hayhurst, A. N. and Parmar, M. S. Does solid carbon burn in oxygen to give the gaseous intermediate $\mathrm{CO}$ or produce $\mathrm{CO}_{2}$ directly? Some experiments in a hot bed of sand fluidized by air. Chem. Eng. Sci., 1998, 53(3), 427-438.

19 Yezerets, A., Currier, N. W., and Eadler, H. A. Experimental determination of kinetics of diesel soot oxidation by $\mathrm{O}_{2}$-modeling consequences. $S A E$ Paper, 2003, no. 2003-01-0833.

20 Graven, W. M. and Long, F. J. Kinetics and mechanisms of the two opposing reactions of the equilibrium $\mathrm{CO}+\mathrm{H}_{2} \mathrm{O}=\mathrm{CO}_{2}+\mathrm{H}_{2}$. J. Am. Chem. Soc., 1954, 76, 2602-2607.

21 Jacquot, F., Logie, V., Brilhac, J. F., and Gilot, P. Kinetics of the oxidation of carbon black by $\mathrm{NO}_{2}$ influence of the presence of water and oxygen. Carbon, 2002, 40(3), 335-343.

22 Olson, K. E., Luss, D., and Amundson, N. R. Regeneration of adiabatic fixed beds. Indl Engng Chem. Process Design Development, 1968, 7, 96-100.

23 Otto, K., Sieg, M. H., Zinbo, M., and Bartosiewicz, L. The oxidation of soot deposits from diesel engines. SAE Paper, 1980, no. 800336.

24 Ishiguro, T., Takatori, Y., and Akihama, K. Microstructure of diesel soot particles probed by electron 
microscopy: first observation of inner core and outer shell. Combustion and Flame, 1997, 108, 231-234.

25 Yezerets, A., Currier, N. W., Eadler, H., Popuri, S., and Suresh, A. Quantitative flow-reactor study of diesel soot oxidation process. SAE Paper, 2002, no. 2002-01-1684.

26 Ahlström, A. F. and Odenbrand, C. U. I. Combustion characteristics of soot deposits from diesel engines. Carbon, 1989, 27(3), 475-583.

27 Neeft, J. P. A., Nijhuis, T. X., Smakman, E., Makkee, M., and Moulijn, J. A. Kinetics of the oxidation of diesel soot. Fuel, 1997, 76(12), 1129-1136.

28 Kilpinen, P., Kallio, S., Konttinen, J., and Barišic, V. Char-nitrogen oxidation under fluidised bed combustion conditions: single particle studies. Fuel, 2002, 81, 2349-2362.

29 Hottel, H. C., Williams, G. C., Nerheim, N. M., and Schneider, G. R. Kinetic studies in stirred reactors: combustion of carbon monoxide and propene. Tenth symposium (international) on Combustion, The Combustion Institute, 1965, pp. 111-121.

30 Johnston, H. S., Bonner, W. A., and Wilson, D. J. Carbon isotope effect during oxidation of carbon monoxide with nitrogen dioxide. J. Chem. Phys., 1957, 26(5), 1002-1006.

31 http://www.iupac-kinetic.ch.com.ac.uk last accessed 16 December 2004.

32 Johnson, T. V. Diesel emission control in reviewthe last 12 months. SAE Paper, 2003, no. 2003-01-0039.

\section{APPENDIX}

\section{Notation}

\begin{tabular}{|c|c|}
\hline$a$ & specific area $\left(\mathrm{m}^{-1}\right)$ \\
\hline$A$ & frequency factor $\left(\mathrm{s}^{-1}\right)$ \\
\hline$A_{\text {fil }}$ & total filtration projected area $\left(\mathrm{m}^{2}\right)$ \\
\hline$b$ & mass transfer rate $\left(\mathrm{s}^{-1}\right)$ \\
\hline$c_{\mathrm{p}}$ & $\begin{array}{l}\text { specific heat capacity at constant } \\
\text { pressure }\left(\mathrm{kJ} \cdot \mathrm{kg}^{-1} \mathrm{~K}^{-1}\right)\end{array}$ \\
\hline $\begin{array}{l}C_{1}, \ldots, C_{5} \\
d\end{array}$ & $\begin{array}{l}\text { polynomial constants (various units) } \\
\text { diameter (m) }\end{array}$ \\
\hline DPF & diesel particulate filter \\
\hline$E_{\mathrm{a}}$ & activation energy $\left(\mathrm{kJ} . \mathrm{kmol}^{-1}\right)$ \\
\hline$h$ & $\begin{array}{l}\text { convective heat transfer coefficient } \\
\left(\mathrm{kJ} \cdot \mathrm{s}^{-1} \cdot \mathrm{m}^{-2} \cdot \mathrm{K}^{1}\right)\end{array}$ \\
\hline$H$ & enthalpy of reaction $\left(\mathrm{kJ} . \mathrm{kg}^{-1}\right)$ \\
\hline$G$ & gas flowrate $\left(\mathrm{kg} \cdot \mathrm{s}^{-1}\right)$ \\
\hline$k$ & chemical reaction rate $\left(\mathrm{s}^{-1}\right)$ \\
\hline
\end{tabular}

$k_{\mathrm{s}} \quad$ bulk thermal conductivity of porous solid $\left(\mathrm{k} . / \mathrm{s}^{-1} \cdot \mathrm{m}^{-1} \cdot \mathrm{K}^{-1}\right)$

$K_{\mathrm{c}} \quad$ equilibrium constant based on molar

concentration (various units)

$K_{\mathrm{p}} \quad$ equilibrium constant based on partial pressures (various units)

$K_{\mathrm{p} \text {,formation }}$ equilibrium constant for species formation (various units)

mass fraction $(-)$

$m$

$N$

PM

ppm

$r$

$R_{\mathrm{u}}$

$t$

$T$

WGS

$Y_{\mathrm{j}}$

$y_{\mathrm{j}}$

$z$

Z

$\beta_{\mathrm{p}}$

$v^{\prime}$

$v^{\prime \prime}$

$\rho$

$\varphi$

Subscripts

$\mathrm{f}$

G

i

j

$\mathrm{p}$

pore

$\mathrm{r}$

Reg

$\mathrm{S}$

W

\section{Superscripts}

$\begin{array}{ll}\prime \prime & \text { per unit area }\left(\mathrm{m}^{-2}\right) \\ \text {. } & \text { per unit volume }\left(\mathrm{m}^{-3}\right) \\ & \text { derivative with respect to time }\left(\mathrm{s}^{-1}\right)\end{array}$ 